\title{
Store-Assistance Management for a Supply Chain with Consumer Return under Consignment Contract
}

\author{
Zhihui Wu, ${ }^{1,2}$ Dongyan Chen, ${ }^{1,2}$ and Hui Yu' \\ ${ }^{1}$ School of Management, Harbin University of Science and Technology, Harbin 150080, China \\ ${ }^{2}$ School of Applied Science, Harbin University of Science and Technology, Harbin 150080, China \\ Correspondence should be addressed to Dongyan Chen; dychen_2004@aliyun.com
}

Received 3 July 2016; Revised 10 December 2016; Accepted 20 December 2016; Published 19 January 2017

Academic Editor: Mohammad D. Aliyu

Copyright (c) 2017 Zhihui Wu et al. This is an open access article distributed under the Creative Commons Attribution License, which permits unrestricted use, distribution, and reproduction in any medium, provided the original work is properly cited.

\begin{abstract}
In this paper, the strategy problems of pricing and store-assistance service investment are investigated for a supply chain with consumer return, where the considered supply chain under consignment contract consists of a single manufacturer and a single retailer. Firstly, we use differential equation to model the evolution of store-assistance service level and depict the effect of storeassistance service level on the return rate. By applying two-stage game, both optimal pricing and store-assistance service strategies are obtained based on the presented optimal control model. Subsequently, the committed dynamic consignment price contract is designed to coordinate and improve the performance of supply chain. Finally, a numerical example is provided to illustrate the impacts of the effectiveness of store-assistance service level and decay rate on the feasible region of corresponding contract.
\end{abstract}

\section{Introduction}

The consignment contract plays a central role in improving the performance of supply chain $[1,2]$. As a result, this contract has attracted considerable attention and is widely applied in the large Internet market, such as Amazon, Alibaba, and Tesco [3, 4]. In fact, the online marketplace does not provide the authentic description of product directly and experiences the products as brick and mortar stores. When actual products do not match with the expected value, the consumer will return these products back to the merchant. From the merchant's perspective, a full-refund return policy is commonly provided to the end consumer in order to improve the market competitiveness of products. Note that a generous return policy would increase the market competitiveness but it will inevitably bring the extra returned costs. As discussed in [5], it is not surprising that there exist differences of the return rate in various industries. For instance, the fashion industry has accounted for approximately 35-40\%. Accordingly, most industries promise a false failure return policy to grab the market share. When handling the false failure return, the store-assistance service strategy was provided by merchants to help consumers know the products better with an intention to reduce the return rate. For example, Best Buy company, as the world's largest household appliance and electronics retailer, has launched a service called Geek Squad which can reduce the return rate effectively and ensure a $20 \%$ rise of its earnings. Therefore, the aim of this paper is to focus on the pricing and store-assistance service strategy problems for the operation management of supply chain under consignment contract.

Since consumer return as an important factor affects the operation decision of supply chain, it becomes an important topic in theoretical research of the effect of return policy on supply chain decision and the coordinate issue of supply chain [14-18]. To be specific, when the retail price is an endogenously given parameter, the effort has been made to investigate how to reduce the negative effect of consumer return in [19]. Subsequently, by distinguishing the unsold and returned products, a new buy-back contract has been designed in [20] to coordinate the supply chain under stochastic circumstance. In [21], by capturing the valuation uncertainty of consumers, the impact of the return policy has been discussed on the performance of supply chain and three contracts have been proposed to coordinate the supply chain based on the presented strategies. In addition, the problems 
TABLE 1: A comparison of the present work with related previous works.

\begin{tabular}{lccccc}
\hline References & Consumer returns reduction & Consignment contract & Static & Dynamic & Coordination \\
\hline$[6]$ & $\mathrm{Y}$ & $\mathrm{N}$ & $\mathrm{Y}$ & $\mathrm{N}$ & $\mathrm{N}$ \\
{$[7]$} & $\mathrm{Y}$ & $\mathrm{N}$ & $\mathrm{Y}$ & $\mathrm{N}$ & $\mathrm{N}$ \\
{$[8]$} & $\mathrm{Y}$ & $\mathrm{N}$ & $\mathrm{Y}$ & $\mathrm{N}$ & $\mathrm{N}$ \\
{$[9]$} & $\mathrm{Y}$ & $\mathrm{N}$ & $\mathrm{N}$ & $\mathrm{N}$ & $\mathrm{N}$ \\
{$[10]$} & $\mathrm{Y}$ & $\mathrm{N}$ & $\mathrm{Y}$ & $\mathrm{N}$ & $\mathrm{Y}$ \\
{$[11]$} & $\mathrm{Y}$ & $\mathrm{N}$ & $\mathrm{Y}$ & $\mathrm{N}$ & $\mathrm{N}$ \\
{$[12]$} & $\mathrm{Y}$ & $\mathrm{N}$ & $\mathrm{N}$ & $\mathrm{N}$ & $\mathrm{N}$ \\
{$[13]$} & $\mathrm{N}$ & $\mathrm{Y}$ & $\mathrm{N}$ & $\mathrm{Y}$ & $\mathrm{Y}$ \\
Our paper & $\mathrm{Y}$ & $\mathrm{Y}$ & &
\end{tabular}

of order and coordination have been studied in [22] for twostage supply chain by taking the positive impact and negative impact of consumer return policy into account.

On the other hand, the store-assistance service can effectively reduce the return rate of products but pay for the corresponding service cost. Hence, the merchant should strike a balance between cost and revenue [12]. To mention just a few, the equilibrium service level and price have been proposed in [8] for two competitive firms. The information revelation mechanism has been discussed in [10], where the store-assistance has been provided to reduce consumer return rate and increase demand. In [11], the return policy of the vendor and the store-assistance policy of retailer have been discussed under vendor-managed inventory circumstance. Recent studies on the consumer return are fruitful and the bulk of these reports have focused primarily on the static model. Recently, the problems of the inventory control and return management under the dynamic background have become hot topics [9, 23-25]. For example, by taking the product design quality into account, the problems of the dynamic pricing decision, the return strategy, and the quality decision have been addressed in [9]. In [26, 27], the dynamic preemptive policy has been studied for the supply chain system. However, it is worth mentioning that the decision analysis problem related to the dynamic consumer return has not been thoroughly investigated for supply chain under consignment contract.

The issues of performance analysis and coordination have been studied for supply chain under consignment contract in [28-31] and complex system under various performance indices [32-35]. For example, the effect from vendor-managed inventory onto two-stage supply chain has been discussed in [28]. As mentioned in [30], when the consignment price and the retail price are exogenously given, there exist suitable conditions where the vendormanaged consignment inventory is better than the retailermanaged consignment inventory. In [31], the optimal pricing and service level decisions have been investigated in two supply chains under vendor-managed inventory and retailermanaged inventory, and the corresponding performance of the channel has been analyzed. It is worthwhile to note that the performance of supply chain is more efficient in the first scenario as mentioned in [31]. Subsequently, based on the results in [31], the customer returns policy has been introduced in [13] and the impact from customer return policy onto consignment contract has been discussed, where it can be seen that customer return policy depends on salvage value of the product. Moreover, it has been revealed in [13] that the vendor-managed consignment inventory is helpful for the performance of supply chain whether the return policy is provided or not. For the issue of contract coordination, the method has been provided in [36] on how to use the payment contract to coordinate the supply chain when the retail price affects demands. Furthermore, the impact from shelf space onto demand has been studied in [37] and two-part tariff contract has been designed to coordinate supply chain system under consignment contract with revenue sharing contract, while the customer return scenario has not been addressed.

Motivated by the above discussions, the operation decision problem is investigated for a supply chain with consumer return under consignment contract. Here, we use differential equation to model evolution of store-assistance service level and depict the effect from service level onto the return rate. By applying the optimal control theory, the optimal pricing and service investment strategies are derived under the centralized and decentralized systems. Meanwhile, the contract is designed to improve the performance of decentralized supply chain. Finally, a numerical example is given to show the change of contract feasible domain with effectiveness of storeassistance service level and other parameters and verify the feasibility of coordination contract. The main contribution of this paper can be summarized as follows: (1) the operation problem of supply chain under consignment is investigated from the perspective of dynamic; and (2) the coordination contract is designed for the supply chain by taking the impact of consumer return into account, which can coordinate the decentralized system in the dynamic environment. To be specific, a systematic comparison between this paper and other related papers is given in Table 1 to show the novelty and advantage of this paper.

\section{The Problem Description and the Basic Model}

We consider a supply chain formed of a manufacturer $\mathrm{M}$ and a retailer $\mathrm{R}$, in which the retailer has a strong reputation and the upstream manufacturer sells his products to the end consumer through the retailer's consignment platform. 
To improve the market competitiveness, the manufacturer provides a false failure full-refund policy to his consumer and requires signing the consignment price contract with retailer. By considering the impact of consumer return, retailer should set a fixed unit consignment price $w$ to manufacturer based on the actual sales, where we can determine the actual sales by subtracting the return amount from the product sales. Clearly, the consumer return may affect the profits of manufacturer and retailer. To get more benefits, both the manufacturer and the retailer invest the store-assistance service level to reduce the return rate. Generally speaking, from the perspective of physical store, the aim of the storeassistance service investments is to ensure that the consumer finds the right products, which is mainly reflected by providing bigger space to display the full assortments/styles of products, installing special equipment to enhance the trial experience, and hiring highly qualified salespeople or training the existing ones to improve their sale experiences [8]. On the other hand, from the perspective of online store, the aim of the store-assistance service investments is to help the consumer make more rational decision, which is mainly reflected by providing the online reference services and offline after-sale services and adding the service with the ability of data mining. Here, the service with the ability of data mining can provide a function that helps the consumers check their own purchase records and finds the purchase records from other consumers. We denote the store-assistance service investments of the retailer and the manufacturer over time $t$ as $u(t)$ and $v(t)$, respectively. Then, the evolution of service level can be given by

$$
\dot{S}(t)=(u(t)+v(t))-\delta S(t)
$$

where $S(t)$ is the store-assistance service level at time $t$ with $S(0)=S_{0}$ and the parameter $\delta$ represents the decay rate. The first term states the store-assistance service investments of supply chain members on the store-assistance service level. The second term reflects the decay of store-assistance service level, and the decay of store-assistance service level can characterize several cases, such as (1) hiring the salespeople with less experience or outdated service style and (2) the requirement of store-assistance service which needs to be improved due to the increasing of the product categories and attributes, which can lead to the decreasing of the original store-assistance service level across the time. The abovementioned cases would result in the decay of the storeassistance service level.

The return rate of product $Q(t)$ can be described by an inversely proportional function of the store-assistance service level as

$$
Q(t)=Q_{\max }(1-\lambda S(t))
$$

where $Q_{\max } \in[0,1)$ is the maximum value of return rate and $\lambda>0$ represents the effectiveness of store-assistance service level to be determined later. Note that the product sold cannot be completely returned in reality and hence we assume that $Q_{\max } \neq 1$.
In addition, the market demand $D(t)>0$ is assumed to depend on retail price $p(t)$ in an additive way; that is,

$$
D(t)=\alpha-\beta p(t)
$$

where $\alpha$ is the market capacity and $\beta$ depicts the effect of the retail price on market demand. Specifically, the consumer who returns the product will stop buying these products; it can be clearly seen in (2) and (3) that the actual sales of the product are given by $D(t)(1-Q(t))$. As in [12], the storeassistance service costs of the manufacturer and the retailer may be described by the means of convex and increasing functions of their own service level; that is,

$$
\begin{aligned}
& C(u(t))=\frac{1}{2} u^{2}(t), \\
& C(v(t))=\frac{1}{2} v^{2}(t) .
\end{aligned}
$$

Throughout this paper, we assume that the production $\operatorname{cost} c=0$. Given an infinite time horizon and a common discount rate $\rho$, the objective functions of the retailer, the manufacturer, and the supply chain are, respectively, expressed as

$$
\begin{aligned}
J_{R} & =\int_{0}^{+\infty} e^{-\rho t}[w(\alpha-\beta p(t))(1-Q(t)) \\
& \left.-\frac{1}{2} u^{2}(t)\right] d t, \\
J_{M} & =\int_{0}^{+\infty} e^{-\rho t}[(p(t)-w)(\alpha-\beta p(t))(1-Q(t)) \\
& \left.-\frac{1}{2} v^{2}(t)\right] d t, \\
J_{C} & =\int_{0}^{+\infty} e^{-\rho t}\left[p(t)(\alpha-\beta p(t))(1-Q(t))-\frac{1}{2} u^{2}(t)\right. \\
& \left.-\frac{1}{2} v^{2}(t)\right] d t .
\end{aligned}
$$

Remark 1. In this paper, we assume that the manufacturer provides a false failure full-refund policy to the consumer, which means the return exists due to the difference between the product property and the expectation of the consumers rather than the failure of the product. The store-assistance considered in this paper can reduce the false failure return effectively. On the other hand, we consider the full-refund policy, and then the profit functions (i.e., (5) and (6)) of the manufacturer and retailer can be obtained together with $c=$ 0 . It is worthwhile to point out that the core of this paper can be formulated immediately in terms of the false failure return and full-refund.

\section{The Optimal Strategies under the Decentralized Decision}

Under the decentralized decision, the manufacturer and the retailer maximize their own profits, respectively. Actually, the 
contract parameters are often fixed from the outset of the game. Once the contract is adopted, the contract parameters are fixed throughout the game. Therefore, the supply chain game can be conceptualized as a two-stage game. In the first stage, the retailer decides the consignment price $w$. In the second stage, both the retailer and the manufacturer make their decisions, respectively. In particular, the retailer determines the store-assistance service investment $u(t)$ and the manufacturer determines the retail price $p(t)$ as well as the store-assistance service investment $v(t)$. On the other hand, as discussed in [38], the established model is shown to have the state-reparability property, which implies that the second stage of game admits a unique subgame equilibrium in both Nash and Stackelberg games. That is, the result of the game is irrespective of the fact whether the moves are simultaneous or sequential.

Now, we are in a position to propose the optimal strategies of supply chain under the decentralized decision.

Theorem 2. Under the decentralized decision, the optimal strategies of supply chain members are given by

$$
\begin{aligned}
w^{*} & =\frac{1}{3 \beta}(2 \alpha+D), \\
p^{d^{*}} & =\frac{1}{6 \beta}(5 \alpha+D), \\
v^{d^{*}} & =\frac{\lambda Q_{\max }(\alpha-D)^{2}}{36 \beta(\rho+\delta)}, \\
u^{d^{*}} & =\frac{\lambda Q_{\max }(\alpha-D)(2 \alpha+D)}{18 \beta(\rho+\delta)},
\end{aligned}
$$

where

$$
\begin{aligned}
D & =\frac{\left(2 B-2 \lambda^{2} Q_{\max }^{2} \alpha^{2}-A\right)}{\left(\alpha \lambda^{2} Q_{\max }^{2}\right)} \\
B= & {\left[2 \beta\left(1-Q_{\max }\right)(\rho+\delta)^{2}+2 \rho \beta \lambda Q_{\max }(\rho+\delta) S_{0}\right.} \\
& \left.+\lambda^{2} Q_{\max }^{2} \alpha^{2}\right] \\
A & =\sqrt{4 B^{2}-C} \\
C & =3 \alpha^{2} \lambda^{2} Q_{\max }^{2}\left(2 B-\lambda^{2} Q_{\max }^{2} \alpha^{2}\right) .
\end{aligned}
$$

Furthermore, the optimal store-assistance service level and the optimal profit functions for supply chain members satisfy

$$
\begin{aligned}
& S^{d}(t)=S_{0} e^{-\delta t}+\frac{\lambda Q_{\max }\left(9 \alpha^{2}-(\alpha-D)(5 \alpha+D)\right)}{36 \beta \delta(\rho+\delta)}(1 \\
& \left.-e^{-\delta t}\right), \\
& J_{R}^{d^{*}}=\frac{(2 \alpha+D)(\alpha-D)}{18 \beta}\left(\frac{1-Q_{\max }}{\rho}+\frac{\lambda Q_{\max } S_{0}}{\rho+\delta}\right. \\
& \left.+\frac{\lambda^{2} Q_{\max }^{2} \alpha(\alpha-D)}{12 \rho \beta(\rho+\delta)^{2}}\right), \\
& J_{M}^{d^{*}}=\frac{(\alpha-D)^{2}}{36 \beta}\left(\frac{1-Q_{\max }}{\rho}+\frac{\lambda Q_{\max } S_{0}}{\rho+\delta}\right. \\
& \left.+\frac{\lambda^{2} Q_{\max }^{2}(3 \alpha+D)(\alpha-D)}{24 \rho \beta(\rho+\delta)^{2}}\right) .
\end{aligned}
$$

Proof. By applying the backward induction, we first derive the retail price of product and the optimal store-assistance service investments of supply chain members for the second stage of game. The optimization problem of manufacturer is

$$
\begin{aligned}
\max _{p>0, v>0} & J_{M}=\int_{0}^{\infty} e^{-\rho t}\left[(p(t)-w)(\alpha-\beta p(t))(1-Q(t))-\frac{1}{2} v^{2}(t)\right] d t \\
\text { s.t. } & \dot{S}(t)=(u(t)+v(t))-\delta S(t), \quad S(0)=S_{0} .
\end{aligned}
$$

Subsequently, the Hamilton function is adopted to address the established optimization model. By using the results from the differential game theory [38], we introduce the costate variable $q=q(t)$ to construct the current-value Hamiltonian for the manufacturer as follows:

$$
\begin{aligned}
H_{M}= & (p(t)-w)(\alpha-\beta p(t))(1-Q(t))-\frac{1}{2} v^{2}(t) \\
& +q(t)(u(t)+v(t)-\delta S(t)),
\end{aligned}
$$

where the costate variable $q(t)$ characterizes the shadow prices of an additionalunit of the store-assistance service level. Substituting (2) into (17), we have

$$
\begin{aligned}
H_{M} & \\
= & (p(t)-w)(\alpha-\beta p(t))\left(1-Q_{\max }+\lambda Q_{\max } S(t)\right) \\
& -\frac{1}{2} v^{2}(t)+q(t)(u(t)+v(t)-\delta S(t)) .
\end{aligned}
$$

Applying the necessary conditions for maximum principle, we obtain

$$
\begin{aligned}
& \frac{\partial H_{M}}{\partial v}=0, \\
& \frac{\partial H_{M}}{\partial S}=\rho q-\dot{q} ;
\end{aligned}
$$


the first-order condition of the manufacturer's profit with respect to the retail price $p(t)$ is written as $\partial H_{M} / \partial p=0$; that is, $p=(\alpha+\beta w) / 2 \beta$. Equation (19) implies that

$$
v=q
$$

Substituting $p$ into (20) and solving the differential equation, one has

$$
q(t)=c e^{(\rho+\delta) t}+\frac{\lambda Q_{\max }(\alpha-\beta w)^{2}}{4 \beta(\rho+\delta)} .
$$

Thus, the optimal store-assistance service investment of manufacturer is

$$
v(t)=c e^{(\rho+\delta) t}+\frac{\lambda Q_{\max }(\alpha-\beta w)^{2}}{4 \beta(\rho+\delta)} .
$$

Once $c \neq 0$, the value of manufacturer's service investment given in (23) will tend to be infinite when $t \rightarrow \infty$, which does not fit the current situation. Therefore, we obtain that $c=0$ holds. Combining the result in (23), the optimal store-assistance service investment of manufacturer under the decentralized decision is given as follows:

$$
v(t)=\frac{\lambda Q_{\max }(\alpha-\beta w)^{2}}{4 \beta(\rho+\delta)}
$$

On the other hand, the retailer's optimization problem is

$$
\begin{array}{ll}
\max _{u>0} & J_{R} \\
& =\int_{0}^{\infty} e^{-\rho t}\left[w(\alpha-\beta p(t))(1-Q(t))-\frac{1}{2} u^{2}(t)\right] d t \\
\text { s.t. } & \dot{S}(t)=(u(t)+v(t))-\delta S(t), \quad S(0)=S_{0} .
\end{array}
$$

And the current-value Hamiltonian for the retailer is given by

$$
\begin{aligned}
H_{R}= & w(\alpha-\beta p(t))\left(1-Q_{\max }+\lambda Q_{\max } S(t)\right) \\
& -\frac{1}{2} u^{2}(t)+\eta(t)(u(t)+v(t)-\delta S(t)),
\end{aligned}
$$

where $\eta(t)$ is a costate variable and satisfies

$$
\dot{\eta}=\rho \eta-\frac{\partial H_{M}}{\partial S}=(\rho+\delta) \eta-\frac{\lambda Q_{\max } w(\alpha-\beta w)}{2} .
$$

Similarly, we solve the optimal control problem of retailer. By utilizing the maximization principle, the optimal storeassistance service investment of retailer is $u(t)=\lambda Q_{\max } w(\alpha-$ $\beta w) / 2(\rho+\delta)$. Next, substituting $u(t)$ and $v(t)$ into differential equation (1) and using the initial conditions of (1), the general solution of differential equation for store-assistance service level $S(t)$ is

$$
S(t)=S_{0} e^{-\delta t}+\frac{\lambda Q_{\max }\left(\alpha^{2}-\beta^{2} w^{2}\right)}{4 \beta \delta(\rho+\delta)}\left(1-e^{-\delta t}\right) .
$$

Subsequently, substituting $p, u$, and $v$ into (5) and (6), respectively, the profits of retailer and manufacturer are as follows:

$$
\begin{aligned}
J_{R}= & \frac{\left(1-Q_{\max }\right) w(\alpha-\beta w)}{2 \rho}+\frac{\lambda Q_{\max } S_{0} w(\alpha-\beta w)}{2(\rho+\delta)} \\
& +\frac{\lambda^{2} Q_{\max }^{2} \alpha w(\alpha-\beta w)^{2}}{8 \rho \beta(\rho+\delta)^{2}}, \\
J_{M}= & \frac{\left(1-Q_{\max }\right)(\alpha-\beta w)^{2}}{4 \rho \beta}+\frac{\lambda Q_{\max } S_{0}(\alpha-\beta w)^{2}}{4 \beta(\rho+\delta)} \\
& +\frac{\lambda^{2} Q_{\max }^{2}(\alpha+3 \beta w)(\alpha-\beta w)^{3}}{32 \rho \beta^{2}(\rho+\delta)^{2}} .
\end{aligned}
$$

In the first stage of game, retailer maximizes its profit $J_{R}$ with respect to consignment price of product $w$ and optimization problem is as follows:

$$
\begin{aligned}
\max _{w>0} J_{R} & \\
= & \frac{\left(1-Q_{\max }\right) w(\alpha-\beta w)}{2 \rho} \\
& +\frac{\lambda Q_{\max } S_{0} w(\alpha-\beta w)}{2(\rho+\delta)} \\
& +\frac{\lambda^{2} Q_{\max }^{2} \alpha w(\alpha-\beta w)^{2}}{8 \rho \beta(\rho+\delta)^{2}} .
\end{aligned}
$$

The first-order condition is $\partial J_{R} / \partial w=0$; that is,

$$
\begin{aligned}
\frac{\partial J_{R}}{\partial w} & \\
= & \frac{3 \alpha \beta \lambda^{2} Q_{\max }^{2}}{8 \rho(\rho+\delta)^{2}} w^{2} \\
& -\left[\frac{\left(1-Q_{\max }\right)}{\rho}+\frac{\lambda Q_{\max } S_{0}}{\rho+\delta}+\frac{\lambda^{2} Q_{\max }^{2} \alpha^{2}}{2 \rho \beta(\rho+\delta)^{2}}\right] \beta w \\
& +\frac{\left(1-Q_{\max }\right) \alpha}{2 \rho}+\frac{\lambda Q_{\max } S_{0} \alpha}{2(\rho+\delta)}+\frac{\lambda^{2} Q_{\max }^{2} \alpha^{3}}{8 \rho \beta(\rho+\delta)^{2}}
\end{aligned}
$$

$=0$.

Then,

$$
\begin{aligned}
w_{1}^{*} & =\frac{2 \alpha}{3 \beta} \\
& +\frac{4 \beta(\rho+\delta)\left[(\rho+\delta)\left(1-Q_{\max }\right)+\lambda Q_{\max } \rho S_{0}\right]+A}{3 \alpha \beta \lambda^{2} Q_{\max }^{2}}, \\
w_{2}^{*} & =\frac{2 \alpha}{3 \beta} \\
& +\frac{4 \beta(\rho+\delta)\left[(\rho+\delta)\left(1-Q_{\max }\right)+\lambda Q_{\max } \rho S_{0}\right]-A}{3 \alpha \beta \lambda^{2} Q_{\max }^{2}},
\end{aligned}
$$


where $A$ is defined as in Theorem 2. Note that $\left(\partial^{2} \prod_{R} /\right.$ $\left.\partial w^{2}\right)\left.\right|_{w=w_{1}^{*}}=\left(1 / 4 \rho(\rho+\delta)^{2}\right) A>0 ;\left.\left(\partial^{2} \prod_{R} / \partial w^{2}\right)\right|_{w=w_{2}^{*}}=$ $-\left(1 / 4 \rho(\rho+\delta)^{2}\right) A<0$; thus the optimal consignment prices of retailers are

$$
\begin{aligned}
w^{*} & =w_{2}^{*}=\frac{1}{3 \beta}(2 \alpha \\
& \left.+\frac{4 \beta(\rho+\delta)\left[(\rho+\delta)\left(1-Q_{\max }\right)+\lambda Q_{\max } \rho S_{0}\right]-A}{\alpha \lambda^{2} Q_{\max }^{2}}\right) .
\end{aligned}
$$

Setting $D=\left(2 B-2 \lambda^{2} Q_{\max }^{2} \alpha^{2}-A\right) /\left(\alpha \lambda^{2} Q_{\max }^{2}\right)$, it is easy to see that $-\alpha<D<0$. Finally, by substituting $w^{*}$ into $p, v$, and $u$, we can obtain the optimal decisions.

It is worth mentioning that the optimal strategies (i.e., optimal pricing $w^{*}, p^{d^{*}}$, and service investments $u^{d^{*}}$ and $v^{d^{*}}$ ) are constants, which are easy to implement from a practical perspective. In addition, we can verify that $w^{*}, p^{d^{*}}, u^{d^{*}}$, and $v^{d^{*}}$ are decreasing functions with respect to $\beta$, which mean that the retailers should set a lower consignment price when the impact $\beta$ from the price onto the market demand becomes higher. Accordingly, the manufacturer should set lower retail price and the supply chain members need to reduce the store-assistance service investments. On the other hand, from expressions (10), (11), (14), and (15), it is not difficult to show that $u^{d^{*}}>v^{d^{*}}$ and $J_{R}^{d^{*}}>J_{M}^{d^{*}}$, which depict that the retailer makes more investment than the manufacturer and the retailer's profit is greater than the manufacturer's profit, respectively. In other words, the proposed assertion in Theorem 2 implies that both the profit and the store-assistance service investments from the retailer and manufacturer are asymmetric, which are consistent with the asymmetry of the profit margins [39].

\section{The Optimal Strategies in the Centralized System}

In this section, we examine the performance of the supply chain in the centralized system. Supply chain members integrate to set the optimal pricing strategy and store-assistance service investments in view of maximizing the total profit of supply chain. In this game, $p(t), u(t)$, and $v(t)$ are decision variables.

Theorem 3. In the centralized system, the optimal strategies of supply chain systems are given by

$$
\begin{aligned}
& p^{c *}=\frac{\alpha}{2 \beta}, \\
& u^{c *}=v^{c *}=\frac{\lambda Q_{\max } \alpha^{2}}{4 \beta(\rho+\delta)} .
\end{aligned}
$$

Furthermore, the optimal store-assistance service level and optimal profit of the total supply chain are

$$
\begin{aligned}
S^{c}(t)= & S_{0} e^{-\delta t}+\frac{\lambda Q_{\max } \alpha^{2}}{2 \beta \delta(\rho+\delta)}\left(1-e^{-\delta t}\right), \\
J_{C}^{*}= & \frac{\left(1-Q_{\max }\right) \alpha^{2}}{4 \rho \beta}+\frac{\lambda Q_{\max } S_{0} \alpha^{2}}{4 \beta(\rho+\delta)} \\
& +\frac{\lambda^{2} Q_{\max }^{2} \alpha^{4}}{16 \rho \beta^{2}(\rho+\delta)^{2}} .
\end{aligned}
$$

Proof. The optimization problem of supply chain members is

$$
\begin{aligned}
\max _{p>0, u>0, v>0} & J_{C}=\int_{0}^{\infty} e^{-\rho t}\left[p(t)(\alpha-\beta p(t))(1-Q(t))-\frac{1}{2} u^{2}(t)-\frac{1}{2} v^{2}(t)\right] d t \\
\text { s.t. } & \dot{S}(t)=(u(t)+v(t))-\delta S(t), \quad S(0)=S_{0} .
\end{aligned}
$$

The current-value Hamiltonian is given by

$$
\begin{aligned}
H_{C}= & p(t)(\alpha-\beta p(t))(1-Q(t))-\frac{1}{2} u^{2}(t) \\
& -\frac{1}{2} v^{2}(t)+\mu(t)(u(t)+v(t)-\delta S(t)) .
\end{aligned}
$$

Applying the necessary conditions for maximum principle, we obtain

$$
\begin{aligned}
& \frac{\partial H_{C}}{\partial u}=0, \\
& \frac{\partial H_{C}}{\partial v}=0, \\
& \frac{\partial H_{C}}{\partial S}=\rho \mu-\dot{\mu},
\end{aligned}
$$

and the first-order condition of the supply chain's profit with respect to the retail price $p(t)$ is written as $\partial H_{C} / \partial p=0$; that is, $p=\alpha / 2 \beta$. Equations (38) and (39) imply that

$$
u=v=\mu \text {. }
$$

Substituting $p$ into (40) and solving the differential equation, one has

$$
\mu(t)=c e^{(\rho+\delta) t}+\frac{\lambda Q_{\max } \alpha^{2}}{4 \beta(\rho+\delta)} .
$$

Similar to proof of Theorem 2, the optimal store-assistance service investments of supply chain are

$$
u^{c}=v^{c}=\frac{\lambda Q_{\max } \alpha^{2}}{4 \beta(\rho+\delta)},
$$


and then $\dot{S}(t)=\lambda Q_{\max } \alpha^{2} / 2 \beta(\rho+\delta)-\delta S(t)$. According to the initial condition $S(0)=S_{0}$, we have $S^{c}(t)=S_{0} e^{-\delta t}+$ $\left(\lambda Q_{\max } \alpha^{2} / 2 \beta \delta(\rho+\delta)\right)\left(1-e^{-\delta t}\right)$. Therefore, the supply chain profit is given by

$$
J_{C}^{*}=\frac{\left(1-Q_{\max }\right) \alpha^{2}}{4 \rho \beta}+\frac{\lambda Q_{\max } S_{0} \alpha^{2}}{4 \beta(\rho+\delta)}+\frac{\lambda^{2} Q_{\max }^{2} \alpha^{4}}{16 \rho \beta^{2}(\rho+\delta)^{2}} .
$$

Remark 4. It follows from Theorems 2 and 3 that $S^{d}(t)$ is the weighted sum of $S_{0}$ and $\lambda Q_{\max }\left(9 \alpha^{2}-(\alpha-D)(5 \alpha+\right.$ $D)) / 36 \beta \delta(\rho+\delta)$, and $S^{c}(t)$ is the weighted sum of $S_{0}$ and $\lambda Q_{\max } \alpha^{2} / 2 \beta \delta(\rho+\delta)$. Moreover, $-2 \alpha<D<0$ implies that $S^{d}(t)<S^{c}(t)$. Hence, $1-\lambda S(t) \geq 0$ holds (i.e., $\lambda S(t) \leq$ 1) if $\lambda S^{c}(t) \leq 1$. Therefore, we can choose the parameter $\lambda$ obeying $\lambda \leq \min \left\{1 / S_{0}, \sqrt{2 \beta \delta(\rho+\delta) / Q_{\max } \alpha^{2}}\right\}$; that is, the effectiveness on decreasing the return rate of the storeassistance service level will not be too high.

Based on the Theorem 3, three viewpoints can be obtained. (1) The optimal pricing and service investments are independent of the time and constants. Maintaining the constant pricing and service strategies are relatively easy to implement from an administrative perspective. (2) When the effectiveness of service level is higher (for larger $\lambda$ ), the manufacturer and the retailer will invest more in store-assistance service investment. Meanwhile, the higher maximum value of return rate will induce more store-assistance service level. (3) Discount rate and decay rate have negative impacts on the corresponding service investments.

Proposition 5. Compared with optimal strategies and profit functions in the decentralized and centralized systems, one has

$$
\begin{aligned}
& p^{d^{*}}>p^{c^{*}}, \\
& u^{c *}>u^{d *}, \\
& v^{c *}>v^{d *}, \\
& J_{C}^{*}>J_{R}^{d *}+J_{M}^{d *} .
\end{aligned}
$$

Proposition 5 shows that the retail price is higher and store-assistance service investments are lower in the decentralized system, which induces that the total profit is lower in the decentralized system. Hence, there is a need to design the appropriate contract so as to improve the efficiency of the system.

\section{Coordination Contract}

Motivated by the coordination method in [39], a committed dynamic consignment price contract is provided to coordinate the supply chain and improve the performance of the decentralized supply chain. Contract provisions are structured as follows. First, the retailer offers a consignment price $w^{E}=K / D(t)(1-Q(t))$, where $K$ is a constant. Second, the manufacturer decides the retail price and store-assistance service investment by maximizing its own profit, while the retailer controls the store-assistance service investment by maximizing the profit of the total supply chain.

Theorem 6. The committed dynamic consignment price contract can coordinate supply chain. That is, under the committed dynamic consignment price contract, the equilibrium strategies are consistent with the centralized solutions.

Proof. Under the committed dynamic consignment price contract, the current-value Hamiltonian of manufacturer is

$$
\begin{aligned}
H_{M}^{E}= & p^{E}(t)\left(\alpha-\beta p^{E}(t)\right)\left(1-Q_{\max }+\lambda Q_{\max } S(t)\right) \\
& -K-\frac{1}{2} v^{2}(t)+q^{E}(t)(u(t)+v(t)-\delta S(t)) .
\end{aligned}
$$

From the first-order condition of manufacturer's profit with respect to the retail price $p(t)$, we have

$$
\begin{aligned}
\frac{\partial H_{M}^{E}}{\partial p} & =\left(1-Q_{\max }+\lambda Q_{\max } S(t)\right)\left(-2 \beta p^{E}(t)+\alpha\right) \\
& =0
\end{aligned}
$$

then

$$
p^{E *}=p^{c *}=\frac{\alpha}{2 \beta}
$$

The manufacturer's current-value Hamiltonian is

$$
\begin{aligned}
H_{M}^{E}= & \frac{\alpha^{2}}{4 \beta}\left(1-Q_{\max }+\lambda Q_{\max } S(t)\right)-K-\frac{1}{2} u^{2}(t) \\
& -\frac{1}{2} v^{2}(t)+q^{E}(t)(u(t)+v(t)-\delta S(t)) .
\end{aligned}
$$

And the retailer's current-value Hamiltonian is

$$
\begin{aligned}
H_{M}^{E}= & \frac{\alpha^{2}}{4 \beta}\left(1-Q_{\max }+\lambda Q_{\max } S(t)\right)-\frac{1}{2} U^{2}(t) \\
& -\frac{1}{2} V^{2}(t)+\eta^{E}(t)(u(t)+v(t)-\delta S(t)) .
\end{aligned}
$$

Similar to proof of Theorem 2, we have

$$
u^{E *}=v^{E *}=u^{c *}=v^{c *}=\frac{\lambda Q_{\max } \alpha^{2}}{4 \beta(\rho+\delta)} .
$$

Thus, the contract can coordinate the supply chain.

When the supply chain is coordinated, the profits of both members are as follows:

$$
\begin{aligned}
J_{R}^{E}= & \frac{K}{\rho}-\frac{\lambda^{2} Q_{\max }^{2} \alpha^{4}}{32 \rho \beta^{2}(\rho+\delta)^{2}}, \\
J_{M}^{E}= & \frac{\left(1-Q_{\max }\right) \alpha^{2}}{4 \rho \beta}+\frac{\lambda Q_{\max } \alpha^{2}}{4 \beta(\rho+\delta)} S_{0} \\
& +\frac{3 \lambda^{2} Q_{\max }^{2} \alpha^{4}}{32 \rho \beta^{2}(\rho+\delta)^{2}}-\frac{K}{\rho} .
\end{aligned}
$$


In order to ensure that both party members are involved in this supply chain coordination contract, the following conditions should be satisfied simultaneously: $J_{R}^{E}>J_{R}^{d^{*}}, J_{M}^{E}>$ $J_{M}^{d^{*}}$; then we can get the following conclusions.

Proposition 7. When $k_{1}<K<k_{2}$, both of supply chain members are willing to be involved in the implementation of this contract, where $k_{1}=\lambda^{2} Q_{\max }^{2} \alpha^{4} / 32 \beta^{2}(\rho+\delta)^{2}+$ $\rho J_{R}^{d^{*}}, k_{2}=\left(1-Q_{\max }\right) \alpha^{2} / 4 \beta+\rho \lambda Q_{\max } S_{0} \alpha^{2} / 4 \beta(\rho+\delta)+$ $3 \lambda^{2} Q_{\max }^{2} \alpha^{4} / 32 \beta^{2}(\rho+\delta)^{2}-\rho J_{M}^{d^{*}}$ and the interval $\left(k_{1}, k_{2}\right)$ is called the feasible region of committed dynamic consignment price contract.

Remark 8. For the addressed problem, the manufacturer pays the consignment fee for the retailer at the end of the period. For this case, the retail price $p(t)$ is fixed when signing the contact made among the supply chain members, and hence the market demand quantity $D(t)$ is deterministic based on (3) at end of the clearing period; that is, the market demand quantity $D(t)$ is equal to the whole sales of the products. In fact, the dynamics of the proposed consignment price contract is reflected by the return rate $Q(t)$ rather than the market demand quantity $D(t)$. Although the return rate $Q(t)$ may be different among different periods, $Q(t)$ is deterministic at the end of the period. Therefore, the developed dynamic consignment price contract can be implemented in reality.

\section{Numerical Analysis}

Based on the results proposed in the above sections, a simulation is given here to illustrate the managerial insights, such as (1) the effects from the price sensitivity $\beta$ and the effectiveness of the store-assistance service level $\lambda$ and the delay rate $\delta$ onto the decisions and profits of the related supply chain, (2) the changes of store-assistance service level and the return rate with time, and (3) the impacts from the price sensitivity $\beta$ and the effectiveness of store-assistance service investment $\lambda$ and the delay rate $\delta$ onto the feasible region $\left(k_{1}, k_{2}\right)$ of dynamic contract. To address these questions, the following parameter values are set in the example: $\alpha=1$, $\beta=0.1, \delta=0.05, Q_{\max }=0.3, \rho=0.1, S_{0}=0.2$, and $\lambda=0.06$.

Define $\Delta J=J_{C}^{*}-J_{R}^{d^{*}}-J_{M}^{d^{*}}\left(J_{C}^{*}>J_{R}^{d^{*}}+J_{M}^{d^{*}}\right)$. According to Theorems 2 and 3, we can obtain Tables $2-4$. From Table 2, we can see that the price sensitivity $\beta$ negatively affects the consignment price and the retail price. The result indicates that, regardless of the centralization and/or decentralization, the higher price sensitivity $\beta$ induces a lower retail price, the store-assistance service investments, and the higher return rate, which leads to lower supply chain profits. Compared with the decentralized equilibria, the store-assistance service investments and profits in the centralized structure are relatively higher. Moreover, the gaps of the investments/profits among two-channel structures shrink with the increasing of $\beta$. It means that the investments/profits in both centralized and decentralized settings decrease with $\beta$, and the declines in centralized case are more faster.
As shown in Table 3, an increasing effectiveness of storeassistance service level $\lambda$ leads to a lower consignment price and the retail price in decentralized channel, but there is no impact on the retail price in the centralized channel. The higher $\lambda$ will lead to more store-assistance service investments and channel profits under centralized and decentralized channels. This result indicates that, regardless of the centralization and decentralization, the channel members are motivated by high effectiveness of the store-assistance service level to invest more in the store-assistance service, which result in a higher store-assistance service level or a lower return rate. Furthermore, the lower return rate and higher (unchanged) demand expanded by lower (unchanged) retail price can jointly contribute to higher supply chain profits. Compared with the decentralized equilibria, the centralized ones are relatively higher, which is consistent with the results in Proposition 5. Moreover, the gaps of investments/profits among two-channel structures enlarge with increasing of effectiveness of the store-assistance service level, which means that the investments/profits in both centralized and decentralized settings increase with $\lambda$; the improvements in centralized case are faster relative to the decentralized one.

Similarly, according to Table 4 , the decay rate $\delta$ of the store-assistance service level will not affect the retail price under the centralized channel, and the effects from $\delta$ onto other equilibria are opposite to the effects from $\lambda$ onto other equilibria. In addition, higher $\delta$ induces lower storeassistance service investments and profits under centralized and decentralized channel. This result indicates that, regardless of the centralization and decentralization, higher $\delta$ induces a lower (unchanged) demand, store-assistance service investments, and the higher return rate, which results in the lower supply chain profits. Compared with the decentralized equilibria, the investments and profits in the centralized structure are relatively higher. Moreover, the gaps of investments/profits among two-channel structures shrink with increasing of decay rate. It means that the investments/profits in both centralized and decentralized settings increase with $\delta$; the declines in centralized case are faster relative to the decentralized case.

Next, from (2), Theorems 2 and 3, and Proposition 7, we have Figures 1-5. Figures 1 and 2 show the changes of store-assistance service level and return rate with time. The impacts from the effectiveness of store-assistance service level and decay rate onto the feasible region of committed dynamic consignment price contract are given in Figures 35. In particular, in Figure 1, we can see that the optimal storeassistance service levels in the centralized decision system are higher than the ones in decentralized decision system due to the fact that the investments of store-assistance service levels are higher in the centralized decision system. Accordingly, the return rate in the centralized decision system is lower than the one in decentralized decision system from Figure 2, which shows that the lower retail price and return rate in the centralized decision system can improve the profit of supply chain.

Figure 3 shows that when $K$ locates between $k_{1}$ and $k_{2}$, the committed dynamic consignment price contract can 
TABLE 2: The impact of the price sensitivity $\beta$ on decisions and profits.

\begin{tabular}{lcccccccccc}
\hline$\beta$ & $w^{*}$ & $p^{d *}$ & $p^{c *}$ & $u^{d *}$ & $u^{c *}\left(v^{c *}\right)$ & $v^{d *}$ & $J_{M}^{d *}$ & $J_{R}^{d *}$ & $J_{C}^{*}$ & $\Delta J$ \\
\hline 0.10 & 4.891 & 7.445 & 5.000 & 0.1999 & 0.400 & 0.1044 & 0.710 & 9.194 & 19.18 & 9.275 \\
0.30 & 1.654 & 2.493 & 1.666 & 0.0667 & 0.133 & 0.0338 & 0.684 & 2.974 & 6.037 & 2.378 \\
0.50 & 0.995 & 1.497 & 1.000 & 0.0400 & 0.080 & 0.0202 & 0.679 & 1.774 & 3.580 & 1.126 \\
0.70 & 0.712 & 1.070 & 0.714 & 0.0286 & 0.057 & 0.0144 & 0.677 & 1.263 & 2.544 & 0.602 \\
0.90 & 0.554 & 0.832 & 0.555 & 0.0222 & 0.044 & 0.0112 & 0.676 & 0.981 & 1.973 & 0.315 \\
\hline
\end{tabular}

TABLE 3: The impact of effectiveness of store-assistance service level $\lambda$ on decisions and profits.

\begin{tabular}{lccccccccccc}
\hline$\lambda$ & $w^{*}$ & $p^{d *}$ & $p^{c *}$ & $u^{d *}$ & $u^{c *}\left(v^{c *}\right)$ & $v^{d *}$ & $J_{M}^{d *}$ & $J_{R}^{d *}$ & $J_{C}^{*}$ & $\Delta J$ \\
\hline 0.005 & 4.999 & 7.499 & 5.0 & 0.0125 & 0.025 & 0.0063 & 4.378 & 8.754 & 17.511 & 4.379 \\
0.020 & 4.992 & 7.496 & 5.0 & 0.0500 & 0.100 & 0.0251 & 4.408 & 8.785 & 17.620 & 4.426 \\
0.035 & 4.978 & 7.489 & 5.0 & 0.0875 & 0.175 & 0.0441 & 4.470 & 8.844 & 17.841 & 4.526 \\
0.050 & 4.956 & 7.478 & 5.0 & 0.1250 & 0.250 & 0.0636 & 4.564 & 8.931 & 18.175 & 4.678 \\
0.065 & 4.927 & 7.463 & 5.0 & 0.0812 & 0.325 & 0.0836 & 4.691 & 9.048 & 18.621 & 4.881 \\
0.080 & 4.891 & 7.445 & 5.0 & 0.1000 & 0.400 & 0.1044 & 4.851 & 9.194 & 19.180 & 5.134 \\
\hline
\end{tabular}

TABLE 4: The impact of decay rate of store-assistance service level $\delta$ on decisions and profits.

\begin{tabular}{lccccccccccc}
\hline$\lambda$ & $w^{*}$ & $p^{d *}$ & $p^{c *}$ & $u^{d *}$ & $u^{c *}\left(v^{c *}\right)$ & $v^{d *}$ & $J_{M}^{d *}$ & $J_{R}^{d *}$ & $J_{C}^{*}$ & $\Delta J$ \\
\hline 0 & 4.864 & 7.432 & 5.0 & 0.224 & 0.450 & 0.118 & 4.976 & 9.308 & 19.615 & 5.331 \\
0.01 & 4.886 & 7.443 & 5.0 & 0.204 & 0.409 & 0.107 & 4.873 & 9.214 & 19.255 & 5.168 \\
0.02 & 4.903 & 7.452 & 5.0 & 0.187 & 0.375 & 0.097 & 4.794 & 9.142 & 18.981 & 5.045 \\
0.03 & 4.917 & 7.458 & 5.0 & 0.173 & 0.346 & 0.089 & 4.732 & 9.086 & 18.767 & 4.949 \\
0.04 & 4.928 & 7.464 & 5.0 & 0.160 & 0.321 & 0.082 & 4.684 & 9.042 & 18.597 & 4.871 \\
0.05 & 4.937 & 7.468 & 5.0 & 0.150 & 0.300 & 0.076 & 4.645 & 9.006 & 18.460 & 4.809 \\
\hline
\end{tabular}

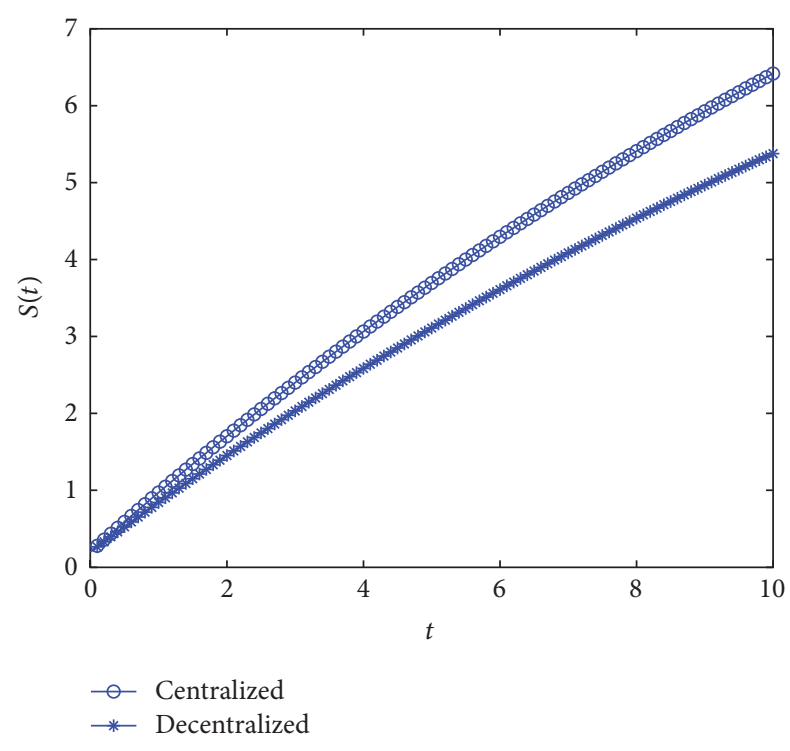

FIgURE 1: The dynamic change of store-assistance service level.

coordinate the supply chain well and both members are better off. Specifically, when the price sensitivity $\beta$ increases, the win-win region becomes smaller. This implies that larger $\beta$ will provide retailer with a smaller degree of flexibility to coordinate the supply chain. Figure 4 depicts that the winwin region becomes large accompanied with the increasing

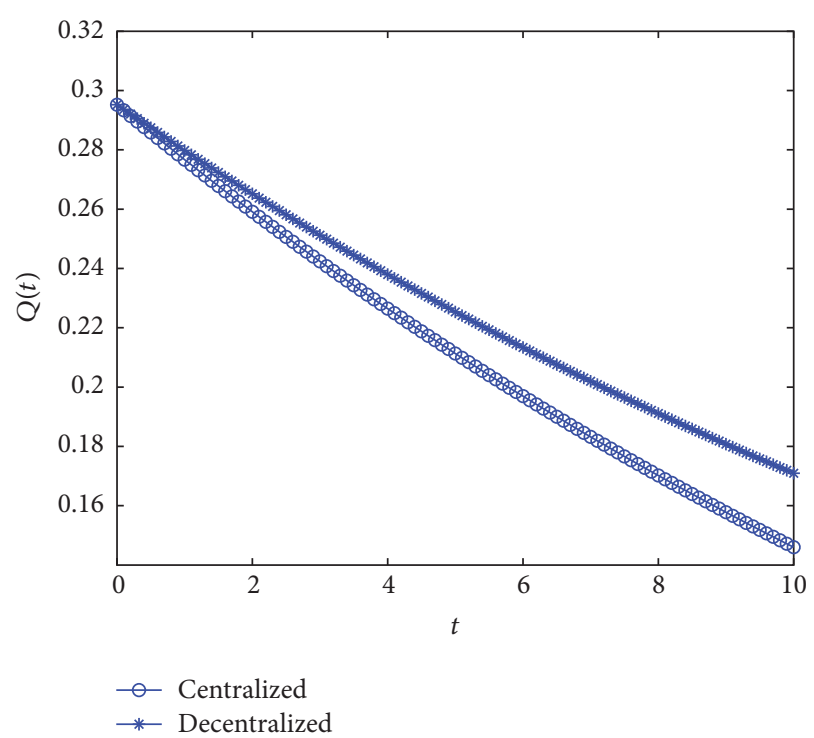

FIGURE 2: The dynamic change of return rate.

of the effectiveness of the store-assistance service level $\lambda$. This implies that larger $\lambda$ will provide retailer with a greater degree of flexibility to coordinate the supply chain. As such, the retailer should analyze the main reason of product return and choose a more effective way to reduce the return rate. 


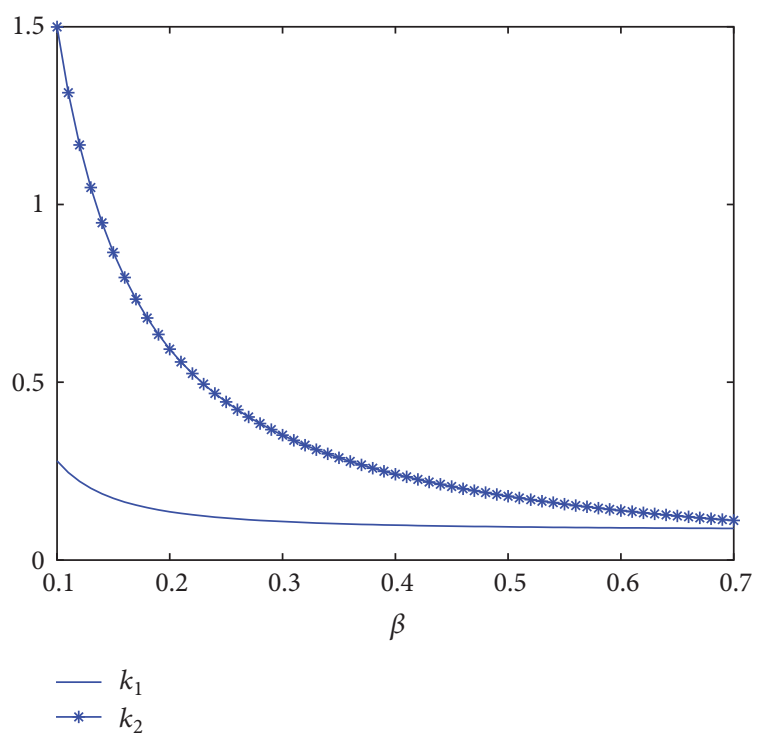

FIgURE 3: The impact of $\beta$ on the feasible region of contract.

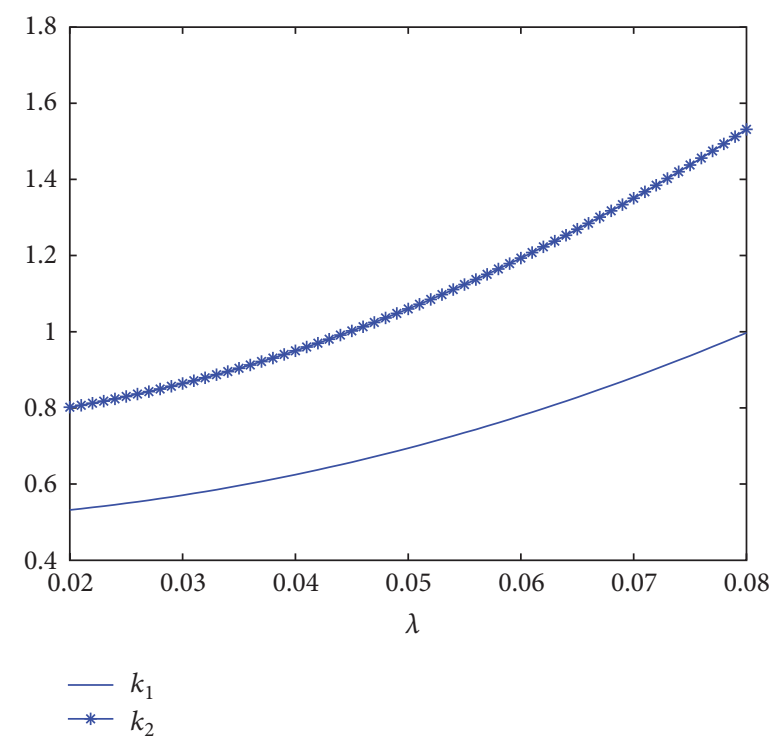

FIgURE 4: The impact of $\lambda$ on the feasible region of contract.

Figure 5 shows that the effects from the decay rate $\delta$ onto winwin region are similar to $\beta$.

\section{Conclusions}

In this paper, we have discussed the decision problems of supply chain subject to the consumer return under consignment contract. By applying the optimal control theory, the strategies of optimal pricing and service have been presented in the decentralized and centralized decision systems. The main novelty lies in the following: (i) the dynamic evolution feature of the store-assistance service level has been considered and the store-assistance service level has been set as a state variable; (ii) by constructing the differential game model, both the pricing and store-assistance service investment strategies

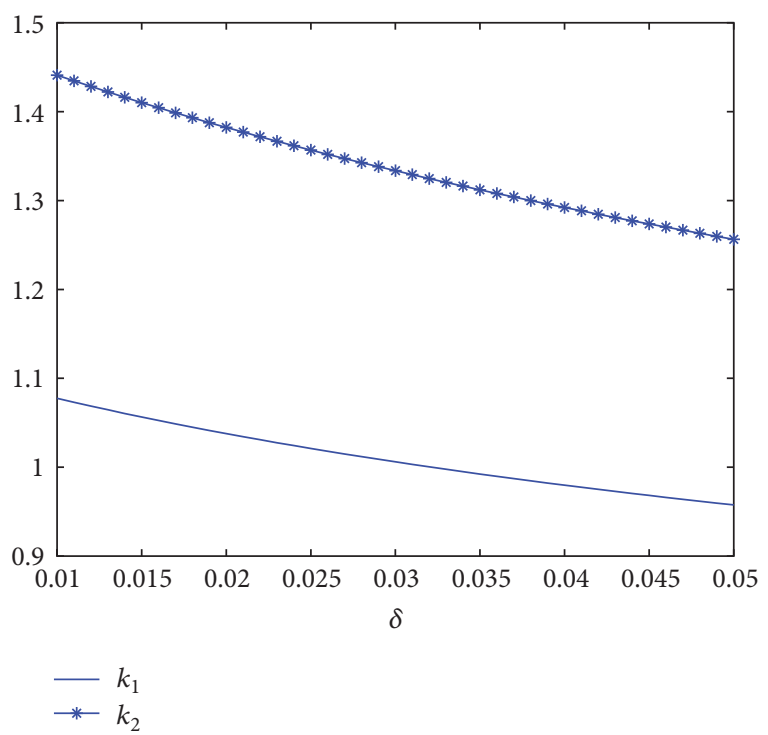

Figure 5: The impact of $\delta$ on the feasible region of contract.

have been given under the centralized and decentralized settings, and a committed dynamic consignment price contract has been designed to coordinate the decentralized supply chain. Finally, a numerical analysis has been conducted to illustrate the effectiveness of the store-assistance service level and price sensitivity on equilibria and coordination. In particular, we have obtained the following results: (1) the optimal retail price is lower and the optimal store-assistance service investments are higher in the centralized setting. As a result, a lower return rate arises in the centralized one. (2) Compared with the store-assistance service investments from the retailer and the manufacturer, it can be seen that the investment from the retailer is higher than the one of the manufacturer in decentralized setting and the effectiveness of the store-assistance service level, the price sensitivity, and the decay rate of store-assistance service level would affect the optimal strategies. (3) The committed dynamic consignment price contract effectively improves the performance of the decentralized supply chain. Future research topics include the extension of the proposed strategies to the performance analysis and scheme design with multiobjective constraints in [40] and to a three-layer supply chain model with multiple manufacturers as in [41].

\section{Competing Interests}

The authors declare that there are no competing interests regarding the publication of this paper.

\section{Acknowledgments}

This work was supported in part by the National Natural Science Foundation of China (Grant 11271103), the Fok Ying Tung Education Foundation of China (Grant 151004), the University Nursing Program for Young Scholars with 
Creative Talents in Heilongjiang Province (Grant UNPYSCT2016029), and the Foundation of Heilongjiang Province of China (Grant QC2015085).

\section{References}

[1] L.-T. Chen, "Dynamic supply chain coordination under consignment and vendor-managed inventory in retailer-centric B2B electronic markets," Industrial Marketing Management, vol. 42, no. 4, pp. 518-531, 2013.

[2] E. Adida and N. Ratisoontorn, "Consignment contracts with retail competition," European Journal of Operational Research, vol. 215, no. 1, pp. 136-148, 2011.

[3] J.-M. Chen, I.-C. Lin, and H.-L. Cheng, "Channel coordination under consignment and vendor-managed inventory in a distribution system," Transportation Research Part E: Logistics and Transportation Review, vol. 46, no. 6, pp. 831-843, 2010.

[4] T. Avinadav, T. Chernonog, and Y. Perlman, "Consignment contract for mobile apps between a single retailer and competitive developers with different risk attitudes," European Journal of Operational Research, vol. 246, no. 3, pp. 949-957, 2015.

[5] J. Chen and P. C. Bell, "The impact of customer returns on supply chain decisions under various channel interactions," Annals of Operations Research, vol. 206, no. 1, pp. 59-74, 2013.

[6] Y. Li, L. Xu, and D. Li, "Examining relationships between the return policy, product quality, and pricing strategy in online direct selling," International Journal of Production Economics, vol. 144, no. 2, pp. 451-460, 2013.

[7] S. H. Yoo, "Product quality and return policy in a supply chain under risk aversion of a supplier," International Journal of Production Economics, vol. 154, pp. 146-155, 2014.

[8] E. Ofek, Z. Katona, and M. Sarvary, "'Bricks and clicks': the impact of product returns on the strategies of multichannel retailers," Marketing Science, vol. 30, no. 1, pp. 42-60, 2011.

[9] S. K. Mukhopadhyay and R. Setaputra, "A dynamic model for optimal design quality and return policies," European Journal of Operational Research, vol. 180, no. 3, pp. 1144-1154, 2007.

[10] T. Xiao and J. Shi, "Consumer returns reduction and information revelation mechanism for a supply chain," Annals of Operations Research, vol. 240, no. 2, pp. 661-681, 2016.

[11] J. Shi and T. Xiao, "Service investment and consumer returns policy in a vendor-managed inventory supply chain," Journal of Industrial and Management Optimization, vol. 11, no. 2, pp. 439459, 2015.

[12] J. Shi and T. Xiao, "Store assistance and coordination of supply chains facing consumer's return," Journal of Industrial and Management Optimization, vol. 12, no. 3, pp. 991-1007, 2016.

[13] W. Hu, Y. Li, and K. Govindan, "The impact of consumer returns policies on consignment contracts with inventory control," European Journal of Operational Research, vol. 233, no. 2, pp. 398-407, 2014.

[14] J. Mostard and R. Teunter, "The newsboy problem with resalable returns: a single period model and case study," European Journal of Operational Research, vol. 169, no. 1, pp. 81-96, 2006.

[15] L. Xu, Y. Li, K. Govindan, and X. Xu, "Consumer returns policies with endogenous deadline and supply chain coordination," European Journal of Operational Research, vol. 242, no. 1, pp. 8899, 2015.

[16] X. Huang, J.-W. Gu, W.-K. Ching, and T.-K. Siu, "Impact of secondary market on consumer return policies and supply chain coordination," Omega, vol. 45, pp. 57-70, 2014.
[17] Y. Li, L. Xu, T.-M. Choi, and K. Govindan, "Optimal advanceselling strategy for fashionable products with opportunistic consumers returns," IEEE Transactions on Systems, Man, and Cybernetics: Systems, vol. 44, no. 7, pp. 938-952, 2014.

[18] J. Liu and Y. He, "Coordinating a supply chain with risk-averse agents under demand and consumer returns uncertainty," Mathematical Problems in Engineering, vol. 2013, Article ID 289572, 10 pages, 2013.

[19] J. Chen and P. C. Bell, "The impact of customer returns on pricing and order decisions," European Journal of Operational Research, vol. 195, no. 1, pp. 280-295, 2009.

[20] J. Chen and P. C. Bell, "Coordinating a decentralized supply chain with customer returns and price-dependent stochastic demand using a buyback policy," European Journal of Operational Research, vol. 212, no. 2, pp. 293-300, 2011.

[21] X. Su, "Consumer returns policies and supply chain performance," Manufacturing \& Service Operations Management, vol. 11, no. 4, pp. 595-612, 2009.

[22] T. Xiao, K. Shi, and D. Yang, "Coordination of a supply chain with consumer return under demand uncertainty," International Journal of Production Economics, vol. 124, no. 1, pp. 171180, 2010.

[23] S. S. Sana, "Demand influenced by enterprises' initiativesa multi-item EOQ model of deteriorating and ameliorating items," Mathematical and Computer Modelling, vol. 52, no. 1-2, pp. 284-302, 2010.

[24] S. S. Sana, "An EOQ model for salesmen's initiatives stock and price sensitive demand of similar products-a dynamical system," Applied Mathematics and Computation, vol. 218, no. 7, pp. 3277-3288, 2011.

[25] S. S. Sana, "An EOQ model of homogeneous products while demand is salesmen's initiatives and stock sensitive," Computers \& Mathematics with Applications, vol. 62, no. 2, pp. 577-587, 2011.

[26] S. D. Flapper, "Introduction to feature cluster on closed-loop supply chains," European Journal of Operational Research, vol. 191, no. 3, article 1205, 2008.

[27] S. D. Flapper, J.-P. Gayon, and L. L. Lim, "On the optimal control of manufacturing and remanufacturing activities with a single shared server," European Journal of Operational Research, vol. 234, no. 1, pp. 86-98, 2014.

[28] M. Gümüş, E. M. Jewkes, and J. H. Bookbinder, "Impact of consignment inventory and vendor-managed inventory for a two-party supply chain," International Journal of Production Economics, vol. 113, no. 2, pp. 502-517, 2008.

[29] S. Li, Z. Zhu, and L. Huang, "Supply chain coordination and decision making under consignment contract with revenue sharing," International Journal of Production Economics, vol. 120, no. 1, pp. 88-99, 2009.

[30] C. C. Lee and W. H. J. Chu, "Who should control inventory in a supply chain?" European Journal of Operational Research, vol. 164, no. 1, pp. 158-172, 2005.

[31] J. Ru and Y. Wang, "Consignment contracting: who should control inventory in the supply chain?" European Journal of Operational Research, vol. 201, no. 3, pp. 760-769, 2010.

[32] H. Shu, S. Zhang, B. Shen, and Y. Liu, "Unknown input and state estimation for linear discrete-time systems with missing measurements and correlated noises," International Journal of General Systems, vol. 45, no. 5, pp. 648-661, 2016.

[33] J. Hu, Z. Wang, S. Liu, and H. Gao, "A variance-constrained approach to recursive state estimation for time-varying complex 
networks with missing measurements," Automatica, vol. 64, pp. 155-162, 2016.

[34] Q. Li, B. Shen, Y. Liu, and F. E. Alsaadi, "Event-triggered H $\infty$ state estimation for discrete-time stochastic genetic regulatory networks with Markovian jumping parameters and timevarying delays," Neurocomputing, vol. 174, pp. 912-920, 2016.

[35] J. Hu, Z. Wang, B. Shen, and H. Gao, "Quantised recursive filtering for a class of nonlinear systems with multiplicative noises and missing measurements," International Journal of Control, vol. 86, no. 4, pp. 650-663, 2013.

[36] D. Zhang, R. de Matta, and T. J. Lowe, "Channel coordination in a consignment contract," European Journal of Operational Research, vol. 207, no. 2, pp. 897-905, 2010.

[37] J.-M. Chen, H.-L. Cheng, and M.-C. Chien, "On channel coordination through revenue-sharing contracts with price and shelf-space dependent demand," Applied Mathematical Modelling, vol. 35, no. 10, pp. 4886-4901, 2011.

[38] F. El Ouardighi, "Supply quality management with optimal wholesale price and revenue sharing contracts: a two-stage game approach," International Journal of Production Economics, vol. 156, pp. 260-268, 2014.

[39] G. Liu, J. Zhang, and W. Tang, "Strategic transfer pricing in a marketing-operations interface with quality level and advertising dependent goodwill," Omega, vol. 56, pp. 1-15, 2015.

[40] J. Hu, Z. Wang, D. Chen, and F. E. Alsaadi, "Estimation, filtering and fusion for networked systems with networkinduced phenomena: new progress and prospects," Information Fusion, vol. 31, pp. 65-75, 2016.

[41] S. S. Sana, J. A. Chedid, and K. S. Navarro, "A three layer supply chain model with multiple suppliers, manufacturers and retailers for multiple items," Applied Mathematics and Computation, vol. 229, pp. 139-150, 2014. 


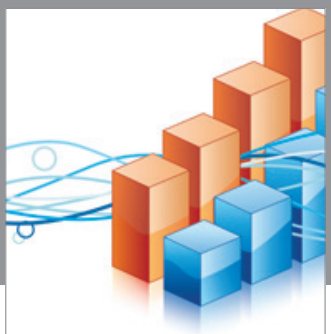

Advances in

Operations Research

vatem alat4

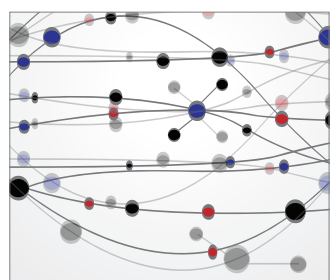

\section{The Scientific} World Journal
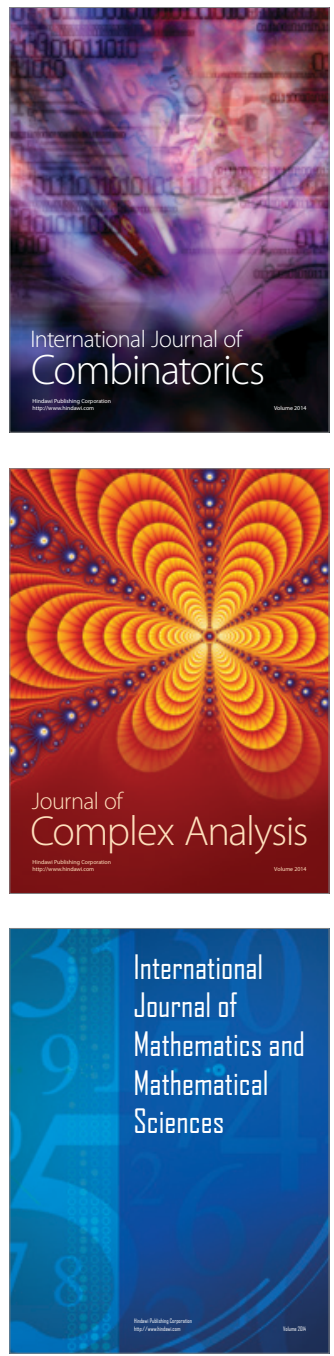
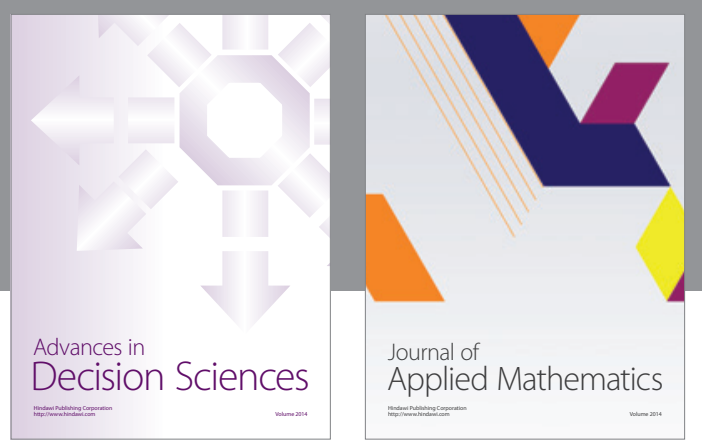

Algebra

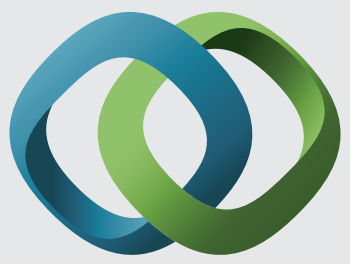

\section{Hindawi}

Submit your manuscripts at

https://www.hindawi.com
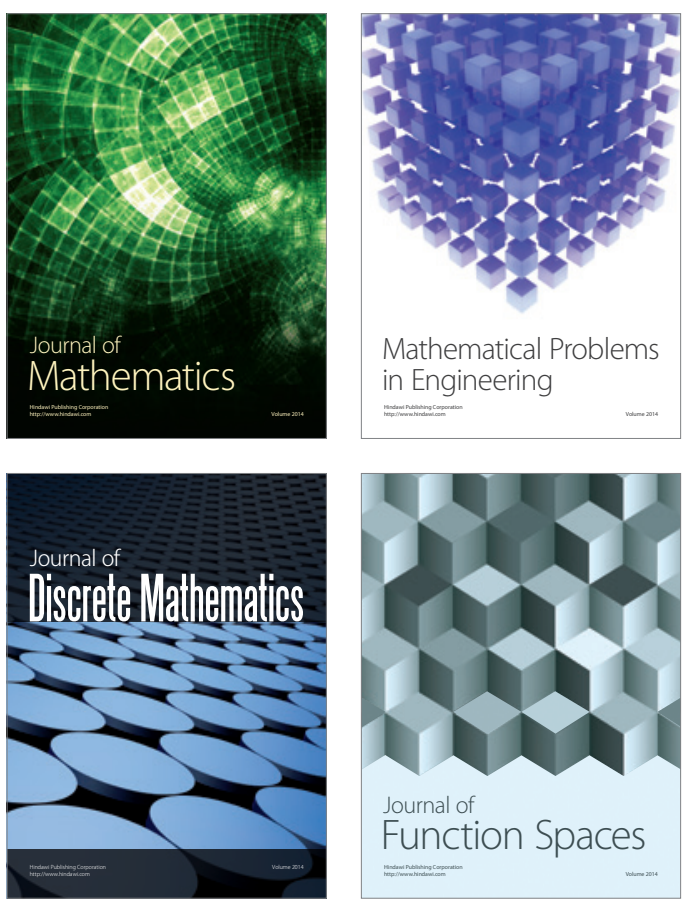

Mathematical Problems in Engineering
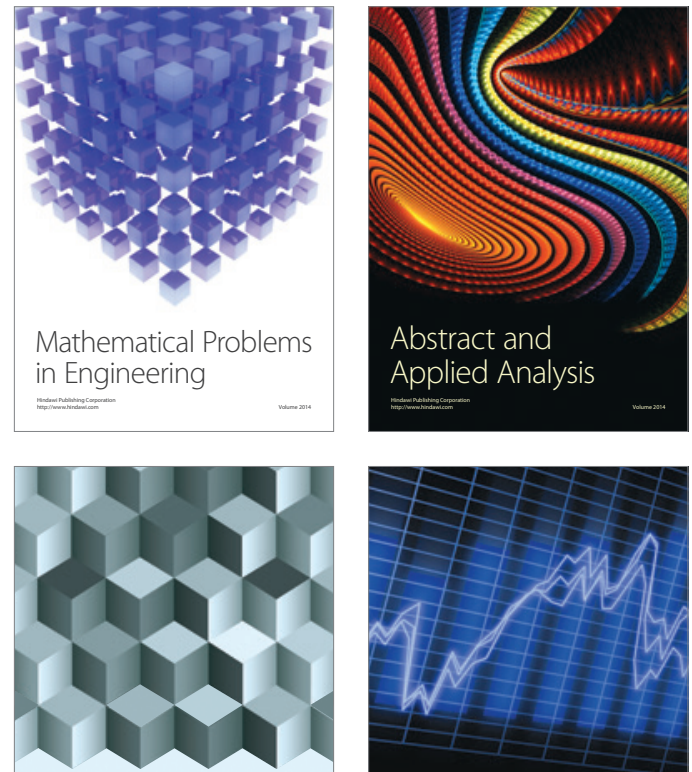

Journal of

Function Spaces

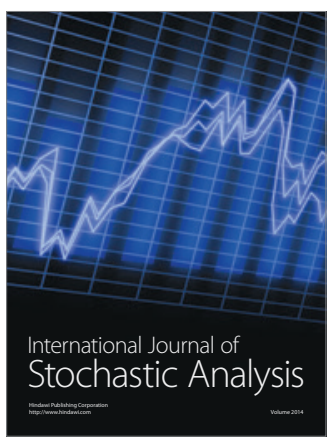

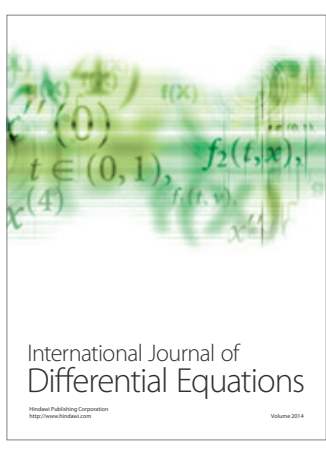
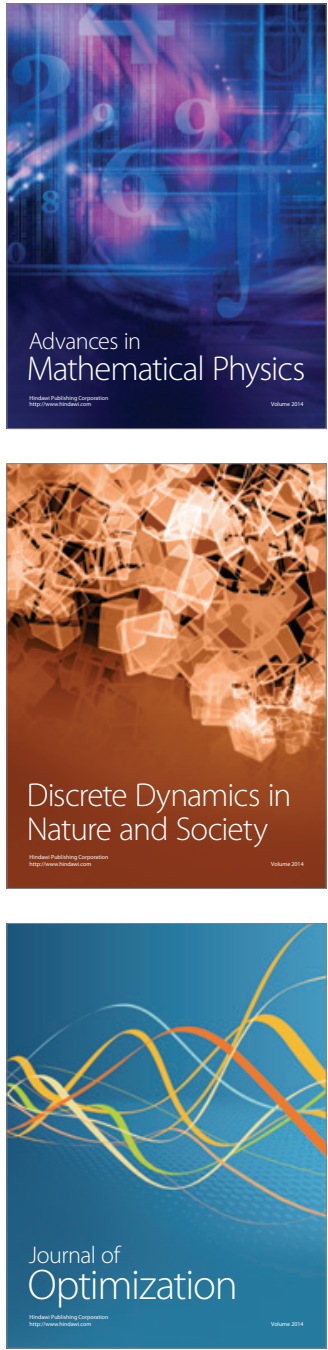